\title{
Risky Sexual Behaviors and Associated Factors among Jiga High School and Preparatory School Students, Amhara Region, Ethiopia
}

\author{
Getachew Mullu Kassa, ${ }^{1}$ Genet Degu, ${ }^{1}$ Meseret Yitayew, ${ }^{2}$ Worku Misganaw, \\ Mikiyas Muche, ${ }^{2}$ Tiguaded Demelash, ${ }^{2}$ Meless Mesele, ${ }^{2}$ and Melat Ayehu ${ }^{2}$ \\ ${ }^{1}$ Midwifery Department, Medicine and Health Sciences College, Debre Markos University, P.O. Box 269, Debre Markos, Ethiopia \\ ${ }^{2}$ Nursing Department, Medicine and Health Sciences College, Debre Markos University, P.O. Box 269, Debre Markos, Ethiopia
}

Correspondence should be addressed to Getachew Mullu Kassa; gechm2005@gmail.com

Received 19 December 2015; Accepted 29 May 2016

Academic Editor: Apolinaras Zaborskis

Copyright ( $) 2016$ Getachew Mullu Kassa et al. This is an open access article distributed under the Creative Commons Attribution License, which permits unrestricted use, distribution, and reproduction in any medium, provided the original work is properly cited.

\begin{abstract}
Background. Young people constitute a large number of population worldwide, and majority of this population group lives in developing countries. They are at high risk of engaging in risky sexual behaviors. These risk sexual behaviors predispose youths to several sexual and reproductive health problems like STIs, HIV, unwanted pregnancy, and abortion. So, this study was conducted to assess the magnitude of risky sexual behaviors and associated factors among Jiga high school and preparatory school students, northwest Ethiopia. Methodology. Institutional based cross-sectional study design was conducted among Jiga town high school and preparatory school students. A total of 311 students were included in the study. Systematic random sampling method was used to select study participants. Data was entered using EpiData version 3.1 and it was exported to SPSS version 22 for further analysis. Descriptive analysis and bivariate and multivariate analysis were also calculated to determine factors associated with risky sexual behavior. Result. Forty-eight (16\%) of respondents reported that they had sexual intercourse. From those who start sex, 44 $(14.7 \%)$ were involved in risky sexual behavior which could predispose them to sexual and reproductive health problems. More than half, 27 (56.3\%), of respondents first sexual intercourse was before their eighteenth birthday. The mean age and SD of fist sexual initiation were 17.2 years old and 1.35 years, respectively. Factors associated with risky sexual behavior include respondents between the ages of 20 and 23 (AOR: 5, 95\%, CI: 1.59-15.98), drinking alcohol (AOR: 2.48, 95\% CI: 1.13-5.41), and having poor knowledge towards HIV/AIDS (AOR: 4.53, 95\%, CI: 2.06-9.94). Conclusion. A large number of in-school youths are involved in risky sexual behaviors like early sexual initiation, having multiple sexual partners, inconsistence use of condom, and having sex with high risk partner (CSWs). Age of respondents, alcohol drinking, and poor knowledge towards HIV/AIDS were factors associated with risky sexual behavior. School and community based programs in reducing substance abuse among youths and increasing their knowledge towards HIV/AIDS are important.
\end{abstract}

\section{Introduction}

More than half of the world population constitutes of young people's less than 25 years old, and majority of these populations live in developing country [1]. Young peoples are at high risk of practicing high risk sexual behaviors, because of the risk taking behavior during this age group $[2,3]$.

In developing countries, the rate of risky sexual behaviors including unprotected sexual intercourse and early sexual initiation is increasing [4]. Studies have showed that more than $50 \%$ of new sexually transmitted diseases (STDs) every year are due to young peoples aged 5 to 24 [5]. Young peoples are engaged in high risk behaviors like smoking cigarettes, drinking alcohol, use of drugs, and gender based violence. These behaviors in turn lead them to engage in sexual risk behaviors [6]. In Ethiopia and many other developing countries, the epidemic of HIV is high among young peoples which is mainly due to the risky sexual behavior [7]. The 
United Nation's Program on HIV/AIDS (UNAIDS) report on the Global AIDS Epidemic showed that sub-Saharan Africa accounts for $60 \%$ of all peoples living with HIV/AIDS [8].

Risk sexual behavior is a behavior related to sexuality which increases the susceptibility of an individual to problems related to sexuality and reproductive health like sexually transmitted disease (STIs), human immune deficiency virus (HIV), unwanted and unplanned pregnancy, abortion, and psychological distress [9-16]. Risk behavior includes having more than one sexual partner, early sexual initiation, inconsistent use of condom, and having sex with commercial sex workers [9, 12-17]. Additionally, the use of substances during sex may engage young peoples in risky sexual behaviors since it affects their judgment [18]. Alcohol use is cited by several studies as it is one of the common factors which increases the risk of HIV acquisition [19].

Such risky sexual behaviors increase the risk of youths to acquire HIV [20]. Addressing the issue of sexual and nonsexual risk behaviors among young peoples is important in reducing the risk of HIV and other STI diseases [6]. So, this study was conducted to assess the magnitude of risky sexual behaviors and associated factors among Jiga high school and preparatory school students, northwest Ethiopia.

\section{Materials and Methods}

2.1. Study Area and Period. The study was conducted in Jiga woreda, West Gojjam, Amhara, Ethiopia. The woreda is $373 \mathrm{~km}$ far from Addis Ababa, the capital city of Ethiopia. The woreda has one high school and one preparatory school. According to 2007 national census conducted by the central statistical agency of Ethiopia (CSA), the woreda has a total population of 28,402 from this 13,917 are male and 14,485 are females. The study was conducted from April to May 2014.

2.2. Study Design and Study Population. School based crosssectional study design was conducted among Jiga high school (grades 9-10) and preparatory school (grades 11-12) students. Study participants were randomly selected from the study population. Regular grade 9 to 12 students were included in to the study, while students who were absent during the data collection period and those who were unable to respond to the questionnaire due to serious illness were excluded from the study.

2.3. Sample Size Determination and Sampling Procedure. Sample size for the study was determined by using single population proportion formula by considering 30\% prevalence of risky sexual behavior, sexually active students, from a study conducted in Oromia region, Bale zone [21], 95\% confidence interval (CI), 5\% margin of error, and 10\% nonresponse rate. In addition, since the total number of students in the schools was 2,216, less than 10,000 correction formula was used, which gives a final sample size of 311. Respondents were selected by using a systematic random sampling method, after proportionally allocating the total number of participants for each grade (grades 9-12).
2.4. Study Variables and Operational Definition. The dependent variable of this study was risky sexual behavior, and the independent variables were sociodemographic characteristics (like age, sex, educational and occupational level, and income), knowledge towards HIV/AIDS, and substance abuse (like alcohol drinking, smoking, chat chewing, and use of drugs like shish/hashish).

Risky sexual behavior is defined as sexually active school students who have at least one of the following: multiple sexual partners, having more than one sexual partner before the data collection period; sexual initiation before the age 18; inconsistent use of condom (incorrect use of condom or failure to use condom at least once during sexual intercourse); and sexual intercourse with commercial sex workers. Respondents who answered/score more than the mean of correct answers for HIV/AIDS related questions were categorized to have good knowledge, while those who responded below the mean of correct answer were classified as having poor knowledge towards HIV/AIDS.

2.5. Data Collection Procedures. Structured self-administered questionnaire, adapted and modified from other study [21], was used to collect data. The questionnaire was first prepared in English then translated to the local language, Amharic, by a person who have good knowledge of both languages. Data was collected by five nursing students from Debre Markos University (DMU).

2.6. Data Processing and Analysis. EpiData version 3.1 software was used to enter the collected data. Then, the data was exported to SPSS software version 22 for further analysis. Descriptive and inferential statics was used to summarize the collected data. Bivariate and multivariate analysis was used to identify factors associated with the dependent variable, at $p$ value less than 0.05 .

2.7. Ethical Consideration. Ethical clearance was obtained from DMU, College of Medicine and Health Science. Prior to the data collection, permission letter was obtained from different levels at Jiga town. Informed consent was obtained from the study participants, after providing the necessary information on the objective, significance, and confidentiality issues of the study.

\section{Results}

3.1. Sociodemographic Characteristics of Respondents. The current study was conducted to assess the risky sexual behaviors and associated factors among Jiga high school and preparatory school students. From a sample of 310, a total of 300 respondents completed the questionnaire which gives a response rate of $96.8 \%$. Majority, 165 (55\%), of respondents were females. Almost two-thirds (62.3\%) of respondents were in the age group of greater than or equal to 18 years old. The mean and standard deviation (SD) for age of respondents were 17.75 years and 1.37 years, respectively. Most, 92\%, of respondents were not married, and $97.7 \%$ were orthodox religion followers. One hundred eighty-eight (62.7\%) of 
TABLE 1: Sociodemographic characteristics of respondents among Jiga high school and preparatory school students, 2014.

\begin{tabular}{|c|c|c|}
\hline Variables & Frequency & Percentage \\
\hline \multicolumn{3}{|l|}{ Sex } \\
\hline Male & 135 & 45 \\
\hline Female & 165 & 55 \\
\hline \multicolumn{3}{|l|}{ Age } \\
\hline$<18$ years old & 113 & 37.7 \\
\hline$\geq 18$ years old & 187 & 62.3 \\
\hline \multicolumn{3}{|l|}{ Mean \pm SD: $17.75 \pm 1.37$} \\
\hline \multicolumn{3}{|l|}{ Marital status } \\
\hline Ever married & 24 & 8 \\
\hline Never married & 276 & 92 \\
\hline \multicolumn{3}{|l|}{ Religion } \\
\hline Orthodox & 293 & 97.7 \\
\hline Muslim & 7 & 2.3 \\
\hline \multicolumn{3}{|l|}{ Ethnicity } \\
\hline Amhara & 300 & 100 \\
\hline \multicolumn{3}{|l|}{ Educational level } \\
\hline Grade 9 & 120 & 40 \\
\hline Grade 10 & 97 & 32.3 \\
\hline Grade 11 & 43 & 14.3 \\
\hline Grade 12 & 40 & 13.3 \\
\hline \multicolumn{3}{|l|}{ Current living condition } \\
\hline With both mother and father & 188 & 62.7 \\
\hline With father only or mother only & 51 & 17 \\
\hline With relatives or friends & 36 & 12 \\
\hline Alone & 25 & 8.3 \\
\hline \multicolumn{3}{|l|}{ Previous residence } \\
\hline Urban & 186 & 62 \\
\hline Rural & 114 & 38 \\
\hline \multicolumn{3}{|l|}{ Father's educational status } \\
\hline Cannot read and write & 81 & 27 \\
\hline Can read and write & 160 & 53.3 \\
\hline Primary education (grades 1-8) & 46 & 15.3 \\
\hline Secondary education (grades 9-12) & 9 & 3 \\
\hline College level and above & 4 & 1.3 \\
\hline \multicolumn{3}{|l|}{ Mother's educational status } \\
\hline Cannot read and write & 147 & 49 \\
\hline Can read and write & 106 & 35.3 \\
\hline Primary education (grade 1-8) & 34 & 11.3 \\
\hline Secondary education (grade 9-12) & 10 & 3.3 \\
\hline College level and above & 3 & 1 \\
\hline
\end{tabular}

respondents currently live with their mothers and fathers, while 25 (8.3\%) live alone (Table 1).

3.2. Sexual History of Respondents. Forty-eight (16\%) of respondents reported that they had sexual intercourse prior to the data collection period. From those who start sex, 44 (14.7\%) were involved in risky sexual behavior which could predispose them to sexual and reproductive health problems. More than half, 27 (56.3\%), of respondents who start sex said
TABLE 2: Sexual history of respondents among Jiga high school and preparatory school students, 2014.

\begin{tabular}{|c|c|c|}
\hline Variables & Frequency & Percentage \\
\hline \multicolumn{3}{|l|}{ Ever had sex } \\
\hline Yes & 48 & 16 \\
\hline No & 252 & 84 \\
\hline \multicolumn{3}{|l|}{ Reason to start sex } \\
\hline Personal desire & 13 & 27.1 \\
\hline Peer pressure & 17 & 35.4 \\
\hline Influence of alcohol & 2 & 4.2 \\
\hline Coercion & 5 & 10.4 \\
\hline Economic problem & 2 & 4.2 \\
\hline $\begin{array}{l}\text { Do not know or do not } \\
\text { remember }\end{array}$ & 9 & 18.8 \\
\hline \multicolumn{3}{|l|}{ Age at first sexual intercourse } \\
\hline$<18$ years old & 27 & 56.3 \\
\hline$\geq 18$ years old & 21 & 43.8 \\
\hline \multicolumn{3}{|l|}{ Mean $\pm \mathrm{SD}=17.2 \pm 1.35$} \\
\hline \multicolumn{3}{|l|}{ Use condom at first sex } \\
\hline Yes & 8 & 16.7 \\
\hline No & 40 & 83.3 \\
\hline \multicolumn{3}{|l|}{ Had sex with CSW } \\
\hline Yes & 3 & 6.3 \\
\hline No & 45 & 93.8 \\
\hline \multicolumn{3}{|c|}{ Total number of sexual partners } \\
\hline One & 34 & 70.8 \\
\hline$\geq$ two & 14 & 29.2 \\
\hline \multicolumn{3}{|l|}{ Risky sexual behavior } \\
\hline No & 256 & 85.3 \\
\hline Yes & 44 & 14.7 \\
\hline \multicolumn{3}{|l|}{$\begin{array}{l}\text { Had sexual intercourse in the } \\
\text { past } 12 \text { months }\end{array}$} \\
\hline Yes & 28 & 58.3 \\
\hline No & 20 & 41.7 \\
\hline
\end{tabular}

that their first sexual intercourse was before their eighteenth birthday. The mean age and SD of first sexual initiation were 17.2 years old and 1.35 years old, respectively. The main reason given by respondents to stat sex was peer pressure followed by personal desire, each accounting for $35.4 \%$ and $27.1 \%$ of the reasons, respectively. Only $8(16.7 \%)$ respondents who start sex used condom during the first sex, while 40 (83.3\%) did not use condom at first sex. In addition, 3 respondents who start sex had sexual intercourse with commercial sex worker (CSW), and 14 (29.2\%) had multiple sexual partner prior to the data collection period. Twenty-eight (58.3\%) had sexual intercourse in the past twelve months (Table 2).

3.3. Knowledge of Respondents towards HIV/AIDS. Majority, $93.3 \%$, of respondents were aware of HIV/AIDS, while 20 (6.7\%) respondents reported that they have never heard of HIV/AIDS. Respondents were also asked to mention the 
modes of HIV transmission. The main mode of HIV transmission listed by respondents was sexual contact, followed by injection with contaminated needles, and mother to child transmission, each accounting for $264(88 \%), 216(72 \%)$, and 213 (71\%), respectively. Eight (2.7\%) and $4(1.3 \%)$ of the respondents said that HIV can be transmitted by hand shaking and by air. Regarding the overall knowledge score, 192 (64\%) respondents had good knowledge towards HIV/AIDS, while $108(36 \%)$ had poor knowledge. In addition, only 19 $(64.3 \%)$ respondents agreed with the idea that condoms prevent pregnancy, and $57(19 \%)$ and 102 (34\%) disagree and do not know that condoms prevent STIs if used properly (Table 3).

3.4. Substance Abuse by Respondents. One hundred thirtytwo of the respondents said that they drank alcohol prior to the data collection period. In addition 14 (4.7\%), 7 (2.3\%), and $5(1.7 \%)$ of the respondents also said that they chew chat, smoke cigarette, and use shisha/hashish, respectively (Table 4).

3.5. Factors Associated with Risky Sexual Behavior. Bivariate and multivariate analysis was computed using SPSS software to identify factors associated with risky sexual behavior. On bivariate analysis, variables which were found to have association with risky sexual behavior include respondents between the ages 20 and 23 (COR: 3.4, 95\% CI: 1.51-7.56); educational level of grade 11 (COR: 0.27 , 95\% CI: 0.090.75); drinking alcohol (COR: 2.87, 95\% CI: 1.47-5.62); ever chewed chat (COR: 6.73, 95\% CI: 2.23-20.28); ever use of shish/hashish (COR: 9.29, 95\% CI: 1.51-57.32); and having poor knowledge towards HIV/AIDS (OR: 3.85, 95\% CI: 1.977.51).

Multivariate logistic regression was also done to identify the independent effect of the variables by controlling the confounding effect of other variables. Accordingly, three variables were found to have association with risky sexual behavior at $p$ value less than 0.05 . These include respondents between the ages of 20 and 23 (AOR: 5, 95\% CI: 1.59-15.98); drinking alcohol (AOR: 2.48, 95\% CI 1.13-5.41); and having poor knowledge towards HIV/AIDS (AOR: 4.53, 95\% CI: 2.06-9.94) (Table 5).

\section{Discussion}

This study assessed the magnitude of risky sexual behavior and associated factors among Jiga high school and preparatory school students.

This study illustrated that $16 \%$ of respondents had sex prior to the data collection period. This finding is lower than a study conducted at Humera, northwest Ethiopia, 21.8\% and a study conducted in western Ethiopia, 35.3\% [13, 15]. Similar findings conducted in Jimma University showed that 26.9\% of respondents started sexual intercourse [22]. This is higher than the current finding. The reason for such difference could be attributed to the difference in sociodemographic characteristics and study population. In addition, the mean age at first sexual intercourse in this study was 17.2 years. This finding is almost similar with study conducted in Jimma
TABLE 3: Knowledge on HIV/AIDS and condom use among Jiga high school and preparatory school students, 2014.

\begin{tabular}{lcc}
\hline Variables & Frequency & Percentage \\
\hline Ever heard of HIV/AIDS & 280 & \\
$\quad$ Yes & 20 & 93.3 \\
No & & 6.7 \\
\hline Modes of HIV transmission* & 264 & \\
Sexual contact & 206 & 68 \\
Blood transfusion & 213 & 71 \\
Mother to child transmission & 216 & 72 \\
Injection with contaminated needles & 190 & 63.3 \\
Through contaminated instruments & 8 & 2.7 \\
Hand shaking & 4 & 1.3 \\
By air & 9 & 3 \\
Do not know & & \\
\hline
\end{tabular}

Healthy looking person can be

infected by HIV

\begin{tabular}{ccc} 
Yes & 211 & 70.9 \\
No & 54 & 18 \\
\hline
\end{tabular}

Healthy looking HIV infected

individual can transmit HIV to

another person

$\begin{array}{lll}\text { Yes } & 200 & 66.7\end{array}$

No $\quad 53 \quad 17.7$

Do not know $\quad 47 \quad 15.7$

Knowledge index

Poor knowledge $\quad 108 \quad 36$

Good knowledge $\quad 192 \quad 64$

Mean \pm SD: $8.3 \pm 1.96$

Condoms prevent pregnancy

Agree $\quad 193 \quad 64.3$

Disagree $\quad 52 \quad 17.3$

Do not know $\quad 55 \quad 18.3$

Condoms make sex less enjoyable

$\begin{array}{lll}\text { Agree } & 95 & 31.7\end{array}$

Disagree $\quad 43 \quad 14.3$

Do not know $\quad 162 \quad 54$

Condoms are easy to use

$\begin{array}{lll}\text { Agree } & 77 & 25.7\end{array}$

Disagree $\quad 66 \quad 22$

Do not know $\quad 157 \quad 52.3$

Condom use is against my religion

$\begin{array}{lcc}\text { Agree } & 108 & 36 \\ \text { Disagree } & 78 & 26 \\ \text { Do not know } & 114 & 38\end{array}$

The price of condom is too high to use regularly

\begin{tabular}{lcc} 
Agree & 42 & 14 \\
Disagree & 117 & 39 \\
Do not know & 141 & 47 \\
\hline Condoms prevent STIs if used properly & & \\
$\quad$ Agree & 141 & 47 \\
Disagree & 57 & 19 \\
Do not know & 102 & 34 \\
\hline
\end{tabular}

${ }^{*}$ Response does not add up to $100 \%$ due to multiple responses. 
TABle 4: Non exual risk behaviors among Jiga high school and preparatory school students, 2014.

\begin{tabular}{lcc}
\hline Variables & Frequency & Percentage \\
\hline Ever drunk alcohol & & \\
$\quad$ No & 168 & 56 \\
Yes & 132 & 44 \\
\hline Ever chew chat & & \\
$\quad$ No & 286 & 95.3 \\
$\quad$ Yes & 14 & 4.7 \\
\hline Ever smoke cigarette & & \\
No & 293 & 97.7 \\
$\quad$ Yes & 7 & 2.3 \\
\hline Ever use shisha/hashish & & \\
No & 295 & 98.3 \\
$\quad$ Yes & 5 & 1.7 \\
\hline
\end{tabular}

University with the mean age at first sexual intercourse being 17.7 years old [22].

More than half, $56.3 \%$, of respondents start sexual intercourse before their eighteenth birthday. This finding is below the Ethiopian Demographic and Health Survey (EDHS) 2011 report, which showed that among women aged 25-49, 62 percent start sexual intercourse before age of 18 [23]. A study conducted in Nigerian University students showed a higher level of sexual initiation (76.8\%) [24]. The possible reason for such difference when compared with the current finding could be due to the sociodemographic characteristics and cultural difference in relation to sexuality and reproductive health between the two countries [22].

From 48 respondents who had sex, only 8 (16.7\%) used condom, and the rest $83.3 \%$ did not used condom at first sex. This kind of risky sexual behavior could predispose young peoples to several sexual and reproductive health problems [9]. Similar findings conducted in Tiss Abay showed that $88.9 \%$ of respondents who start sex did not use condom at first sex [9]. This is slightly higher than the current study finding. The possible explanation for the difference could be the difference in sample size and the study population; the study in Tiss Abay included only female youths, while the current study includes both male and female in-school youths. The United States national survey on youth risk behavior report also showed that $40 \%$ of teenagers engage in sexual activity without the use of condom [25].

The magnitude of risky sexual behavior in the current study area was found to be $14.7 \%$. From this, $56.3 \%$ start sex before the age of $18,83.3 \%$ did not use condom at first sex, $6.3 \%$ had sex with CSW, and $29.2 \%$ had multiple sexual partners. A study conducted in Humera town showed that $13.7 \%$ of respondents were involved in risky sexual behaviors [15]. The higher level of risky sexual behavior was seen in studies conducted in Jimma zone (42.1\%) [12]. A study conducted among Tiss Abay female students also showed a high (70.3\%) level of risky sexual behavior when compared with current study [9]. Possible explanation could be attributed to the reasons mentioned above.

The current study also found three variables which were found to have association with risky sexual behavior at $p$ value less than 0.05 . These variables include respondents between the ages of 20 and 23, drinking alcohol, and having poor knowledge towards HIV/AIDS. Respondents who were in the age group of 20 to 23 were found to be five times more likely to engage in risky sexual behavior when compared with youth in the age group of 14 to 19 years old. This could be because of the physical and psychological maturity of older youths, and the risk taking behavior among these age groups, resulting in increased risk of involving in sexual practice as the age increases. Similar findings were also observed in a study conducted in Jimma University [22].

Youths who drink alcohol were more than two times more likely to engage in risky sexual behavior. This could be because youths who abuse substances like alcohol may have poor judgment, which may result in risky sexual behavior. Similar findings were also observed in studies conducted in Tiss Abay, southwest Ethiopia and northwest Ethiopia [9, 26, 27]. In addition, studies have showed that youths who drink alcohol are more likely to engage in risky sexual behaviors like having multiple sexual partners, performing unprotected sexual intercourse, and having sex with high risk partners like commercial sex workers [2, 16, 27-30].

Students who have poor knowledge towards HIV/AIDS were more than four times more likely to engage in risky sexual behavior. This could be because of the lack of knowledge on HIV transmission and on ways of HIV prevention and the cumulative risk to engage in unprotected sex.

This study has certain limitations. Due to the nature of the cross-sectional study design, it may be difficult to make a causal inference. There may be recall bias among respondents when responding to some of the variables in this study.

\section{Conclusion and Recommendation}

A large number of in-school youths were involved in risky sexual behaviors like early sexual initiation, having multiple sexual partners, inconsistence use of condom, and having sex with high risk partner (CSWs). These behaviors are predisposing youths to several forms of sexual and reproductive health problems. Factors which were found to have association with risky sexual behavior include age of respondent's (20 to 23 years old), alcohol drinking, and having poor knowledge towards HIV/AIDS. So, school and community based programs to strengthen preventive measures, like reducing substance abuse among youths and increasing their knowledge towards HIV/AIDS, are important. Youths should also be encouraged to attend the sexual and reproductive health centers, and such centers should be strengthened. Awareness creation on condom use and risk sexual behavior and its consequences should be done through the available media of communication and comprehensive education on sexual and reproductive health issues should be included to the existing curriculum for high school and preparatory students. 
TABLE 5: Factors associated with risky sexual behaviors among Jiga high school and preparatory school students, 2014.

\begin{tabular}{|c|c|c|c|c|c|}
\hline \multirow{2}{*}{ Variables } & \multicolumn{2}{|c|}{ Risky sexual behavior } & \multirow{2}{*}{ COR $(95 \%$ CI $)$} & \multirow{2}{*}{$\mathrm{AOR}(95 \% \mathrm{CI})$} & \multirow{2}{*}{$p$-value } \\
\hline & No $n(\%)$ & Yes $n(\%)$ & & & \\
\hline \multicolumn{6}{|l|}{ Sex } \\
\hline Male & $113(83.7)$ & $22(16.3)$ & 1 & 1 & \\
\hline Female & $143(86.7)$ & $22(13.3)$ & $0.79(0.42,1.49)$ & $0.49(0.16,1.52)$ & 0.213 \\
\hline \multicolumn{6}{|l|}{ Age } \\
\hline $14-19$ years old & $233(87.6)$ & $33(12.4)$ & 1 & 1 & \\
\hline 20-23 years old & $23(67.6)$ & $11(32.4)$ & $3.4(1.51,7.56)$ & $5(1.59,15.98)$ & 0.006 \\
\hline \multicolumn{6}{|l|}{ Educational level } \\
\hline Grade 9 & $99(82.5)$ & $21(17.5)$ & 1 & 1 & \\
\hline Grade 10 & $89(91.8)$ & $8(8.2)$ & $0.64(0.27,1.49)$ & $0.44(0.17,1.14)$ & 0.090 \\
\hline Grade 11 & $38(88.4)$ & $5(11.6)$ & $0.27(0.09,0.75)$ & $0.91(0.26,3.13)$ & 0.879 \\
\hline Grade 12 & $30(75)$ & $10(25)$ & $0.39(0.12,1.28)$ & $0.63(0.19,2.09)$ & 0448 \\
\hline \multicolumn{6}{|l|}{ Previous residence } \\
\hline Urban & $155(83.3)$ & $31(16.7)$ & $1.55(0.78,3.11)$ & $1.36(0.57,3.21)$ & 0.488 \\
\hline Rural & $101(88.6)$ & $13(11.4)$ & 1 & & \\
\hline \multicolumn{6}{|l|}{ Father's educational status } \\
\hline Cannot read and write & $204(84.6)$ & $37(15.4)$ & $0.99(0.21,4.69)$ & $1.73(0.18,16.51)$ & 0.634 \\
\hline Primary education (grades $1-8$ ) & $41(89.1)$ & $5(10.9)$ & $0.67(0.11,3.94)$ & $0.59(0.05,6.49)$ & 0.667 \\
\hline Secondary (grades 9-12) and college level education & $11(84.6)$ & $2(15.4)$ & 1 & & \\
\hline \multicolumn{6}{|l|}{ Mother's educational status } \\
\hline Cannot read and write & $216(85.4)$ & $37(14.6)$ & $0.94(0.2,4.42)$ & $0.74(0.079,6.96)$ & 0.794 \\
\hline Primary education (grades $1-8$ ) & $29(85.3)$ & $5(14.7)$ & $0.95(0.16,5.63)$ & $1.009(0.097,10.53)$ & 0.994 \\
\hline Secondary (grades 9-12) and college level education & $11(84.6)$ & $2(15.4)$ & 1 & & \\
\hline \multicolumn{6}{|l|}{ Ever drunk alcohol } \\
\hline No & $153(91.1)$ & $15(8.9)$ & 1 & & \\
\hline Yes & $103(78)$ & $29(22)$ & $2.87(1.47,5.62)$ & $2.48(1.13,5.41)$ & 0.023 \\
\hline \multicolumn{6}{|l|}{ Ever chew chat } \\
\hline No & $249(87.1)$ & $37(12.9)$ & 1 & & \\
\hline Yes & $7(50)$ & $7(50)$ & $6.73(2.23,20.28)$ & $2.76(0.69,11.09)$ & 0.152 \\
\hline \multicolumn{6}{|l|}{ Ever use shisha/hashish } \\
\hline No & $254(86.1)$ & $41(13.9)$ & 1 & & \\
\hline Yes & $2(40)$ & $3(60)$ & $9.29(1.51,57.32)$ & $3.33(0.35,31.95)$ & 0.297 \\
\hline \multicolumn{6}{|l|}{ Knowledge towards HIV/AIDS } \\
\hline Poor knowledge & $80(74.1)$ & $28(25.9)$ & $3.85(1.97,7.51)$ & $4.53(2.06,9.94)$ & 0.000 \\
\hline Good knowledge & $176(91.7)$ & $16(8.3)$ & 1 & 1 & \\
\hline \multicolumn{6}{|l|}{ Living arrangement } \\
\hline Living with parents & $200(83.7)$ & $39(16.3)$ & 1 & 1 & \\
\hline Living away from parent & $56(91.8)$ & $5(8.2)$ & $0.46(0.17,1.22)$ & $0.49(0.16,1.52)$ & 0.213 \\
\hline
\end{tabular}

\section{Competing Interests}

The authors declare that they have no competing interests.

\section{Authors' Contributions}

Meseret Yitayew, Worku Misganaw, Mikiyas Muche, Tiguaded Demelash, Meless Mesele, and Melat Ayehu participated in the design, data collection and participated in data analysis and interpretation. Getachew Mullu Kassa and Genet Degu also participated in the data analysis, interpretation, and drafting of the paper. All authors read and approved the final paper.

\section{Acknowledgments}

The authors would like to acknowledge Debre Markos University, College of Medicine and Health Science, for data collectors and study participants.

\section{References}

[1] UNFPA and The State of World Population, People and Possibilities in a World of 7 Billion, 2011.

[2] Z. Alamrew, M. Bedimo, and M. Azage, "Risky sexual practices and associated factors for HIV/AIDS infection among private 
college students in Bahir Dar City, Northwest Ethiopia," ISRN Public Health, vol. 2013, Article ID 763051, 9 pages, 2013.

[3] C. F. Chick and V. F. Reyna, "A fuzzy trace theory of adolescent risk taking: beyond self-control and sensation seeking," in The Adolescent Brain, pp. 379-428, American Psychological Association, Washington, DC, USA, 2012.

[4] S. Yi, K. C. Poudel, J. Yasuoka, P. H. Palmer, S. Yi, and M. Jimba, "Role of risk and protective factors in risky sexual behavior among high school students in Cambodia," BMC Public Health, vol. 10, article 477, 2010.

[5] M. J. Trepka, S. Kim, V. Pekovic, P. Zamor, E. Velez, and M. V. Gabaroni, "High-risk sexual behavior among students of a minority-serving university in a community with a high HIV/AIDS prevalence," Journal of American College Health, vol. 57, no. 1, pp. 77-84, 2008.

[6] X. Tu, C. Lou, E. Gao, N. Li, and L. S. Zabin, "The relationship between sexual behavior and nonsexual risk behaviors among unmarried youth in three Asian cities," Journal of Adolescent Health, vol. 50, no. 3, pp. S75-S82, 2012.

[7] T. S. Mengistu, A. T. Melku, N. D. Bedada, and B. T. Eticha, "Risks for STIs/HIV infection among Madawalabu University students, Southeast Ethiopia: a cross sectional study," Reproductive Health, vol. 10, article 38, 2013.

[8] UNAIDS, 2006 Report on the Global AIDS Sepidemic, 2006.

[9] G. Tadesse and B. Yakob, "Risky sexual behaviors among female youth in Tiss Abay, a semi-urban area of the Amhara Region, Ethiopia," PLoS ONE, vol. 10, no. 3, Article ID e0119050, 2015.

[10] N. Fentahun and A. Mamo, "Risky sexual behaviors and associated factors among male and female students in Jimma Zone preparatory schools, South West Ethiopia: comparative study," Ethiopian Journal of Health Sciences, vol. 24, no. 1, pp. 59-68, 2014.

[11] G. Tura, F. Alemseged, and S. Dejene, "Risky sexual behavior and predisposing factors among students of Jimma University, Ethiopia," Ethiopian Journal of Health Sciences, vol. 22, no. 3, pp. 170-180, 2012.

[12] M. Abebe, A. Tsion, and F. Netsanet, "Living with parents and risky sexual behaviors among preparatory school students in Jimma zone, South west Ethiopia," African Health Sciences, vol. 13, no. 2, pp. 498-506, 2013.

[13] E. L. Negeri, "Assessment of risky sexual behaviors and risk perception among youths in Western Ethiopia: the influences of family and peers: A Comparative Cross-Sectional Study," BMC Public Health, vol. 14, no. 1, article 301, 2014.

[14] J. A. Imaledo, O. B. Peter-Kio, and E. O. Asuquo, "Pattern of risky sexual behavior and associated factors among undergraduate students of the University of Port Harcourt, Rivers State, Nigeria," The Pan African Medical Journal, vol. 12, article 97, 2012.

[15] A. F. Dadi and F. G. Teklu, "Risky sexual behavior and associated factors among grade 9-12 students in Humera secondary school, western zone of Tigray, NW Ethiopia, 2014," Science Journal of Public Health, vol. 2, no. 5, pp. 410-416, 2014.

[16] W. Mulu, T. Demilie, M. Yimer, K. Meshesha, and B. Abera, "Dental caries and associated factors among primary school children in Bahir Dar city: a cross-sectional study," $B M C$ Research Notes, vol. 11, article 84, 2014.

[17] M. L. Cooper, "Alcohol use and risky sexual behavior among college students and youth: evaluating the evidence," Journal of Studies on Alcohol, vol. 63, supplement 14, pp. 101-117, 2002.
[18] S. E. Woolf-King, T. M. Rice, H.-H. M. Truong, W. J. Woods, R. C. Jerome, and A. W. Carrico, "Substance use and HIV risk behavior among men who have sex with men: the role of sexual compulsivity," Journal of Urban Health, vol. 90, no. 5, pp. 948952, 2013.

[19] S. E. Woolf-King and S. A. Maisto, "Alcohol use and highrisk sexual behavior in Sub-Saharan Africa: a narrative review," Archives of Sexual Behavior, vol. 40, no. 1, pp. 17-42, 2011.

[20] U.S. Department of Health and Human Services, Centers for Disease Control and Prevention. Vital Signs: HIV Infection, Testing, and Risk Behaviors Among Youths United States, 2012.

[21] N. Ibrahim, M. Addisse, and N. Deyassa, Factors that influences school adolescents exposure to HIV/STD in Bale, Oromia region [Mph thesis], 2004.

[22] G. Tura, F. Alemseged, and S. Dejene, "Risky sexual behavior and predisposing factors among students of Jimma university, Ethiopia," Ethiopian Journal of Health Sciences, vol. 22, no. 3, pp. 170-180, 2012.

[23] Central Statistical Agency, Ethiopia Demographic and Health Survey 2011. Addis Ababa, Ethiopia, ICF International, Calverton, Md, USA, 2012.

[24] I. I. Okafor and S. N. Obi, "Sexual risk behaviour among undergraduate students in Enugu, Nigeria," Journal of Obstetrics and Gynaecology, vol. 25, no. 6, pp. 592-595, 2005.

[25] L. Kann, R. Lowry, D. Eaton, and H. Wechsler, "Trends in HIVrelated risk behaviors among high school students-United States, 1991-2011," Morbidity and Mortality Weekly Report, vol. 61, no. 29, pp. 556-560, 2012.

[26] K. Tiruneh, B. Wasie, and H. Gonzalez, "Sexual behavior and vulnerability to HIV infection among seasonal migrant laborers in Metema district, northwest Ethiopia: a cross-sectional study," BMC Public Health, vol. 15, article 122, 2015.

[27] N. Fentahun and A. Mamo, "Risky sexual behaviors and associated factors among male and female students in Jimma Zone preparatory schools, South West Ethiopia: comparative study.", Ethiopian journal of health sciences, vol. 24, no. 1, pp. 5968, 2014.

[28] M. L. Cooper, "Alcohol use and risky sexual behavior among college students and youth: evaluating the evidence," Journal of Studies on Alcohol, vol. 63, no. 14, pp. 101-117, 2002.

[29] O. Kalina, A. M. Geckova, P. Jarcuska, O. Orosova, J. P. Van Dijk, and S. A. Reijneveld, "Psychological and behavioural factors associated with sexual risk behaviour among Slovak students," BMC Public Health, vol. 9, article 15, 2009.

[30] J. W. Miller, T. S. Naimi, R. D. Brewer, and S. E. Jones, "Binge drinking and associated health risk behaviors among high school students," Pediatrics, vol. 119, no. 1, pp. 76-85, 2007. 


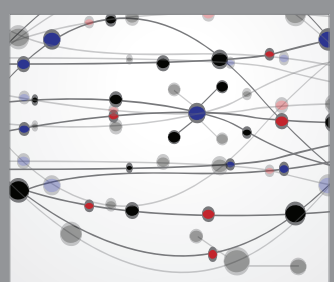

The Scientific World Journal
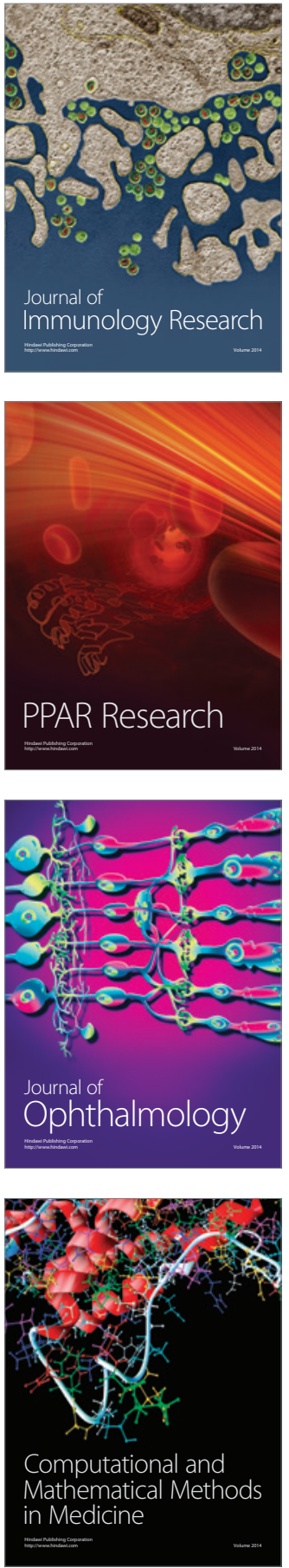

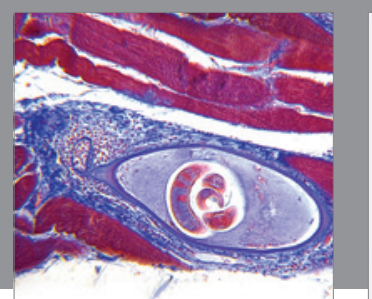

Gastroenterology Research and Practice

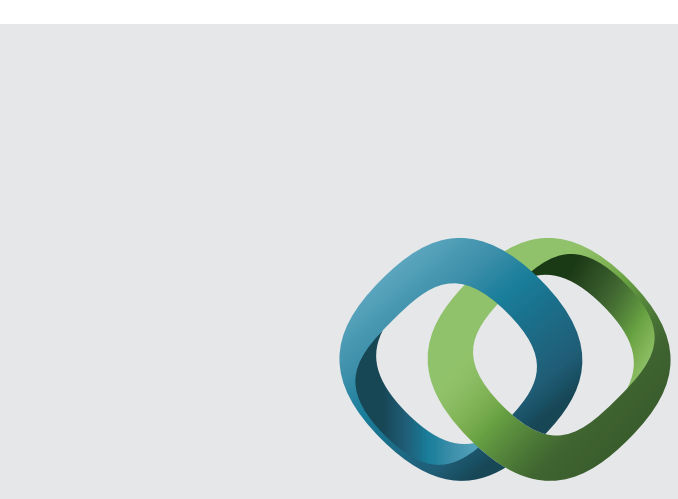

\section{Hindawi}

Submit your manuscripts at

http://www.hindawi.com
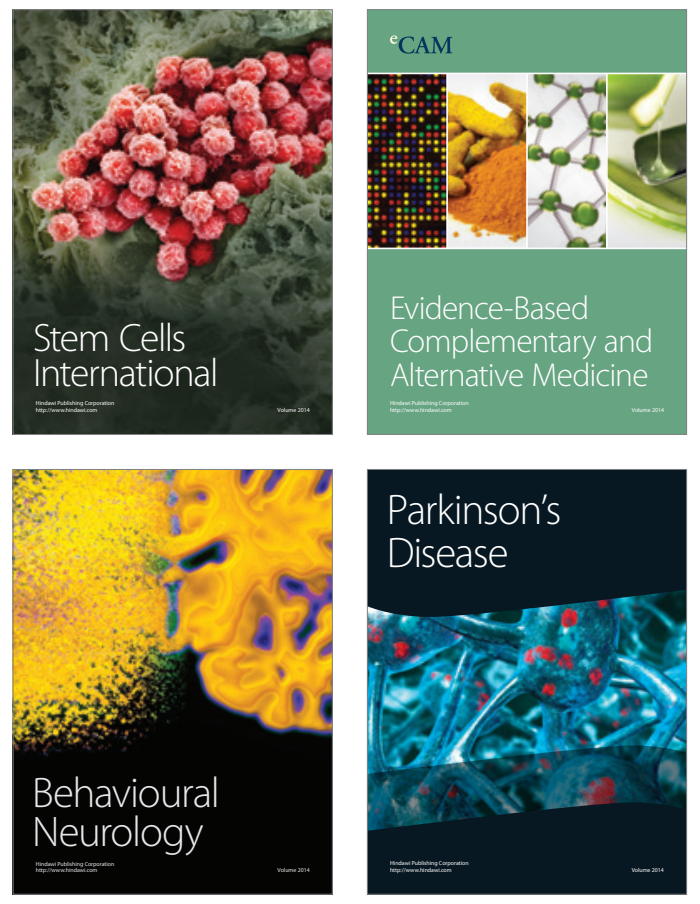
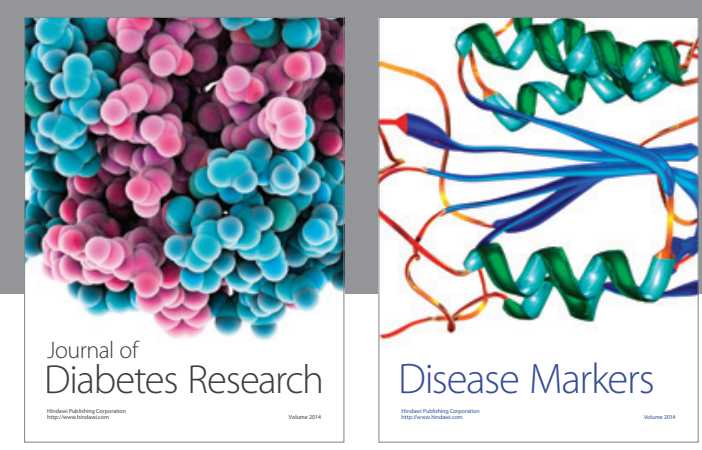

Disease Markers
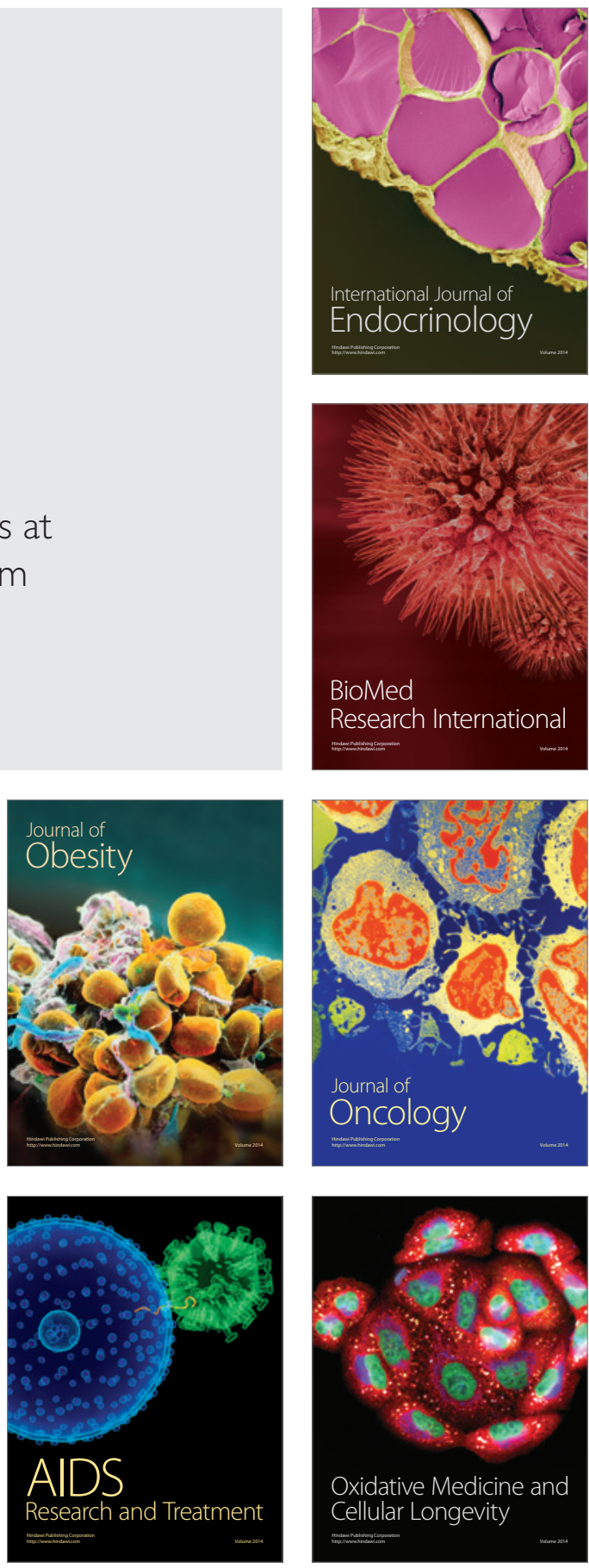